\title{
Editorial Expression of Concern: Water and sodium in heart failure: a spotlight on congestion
}

\author{
Gaspare Parrinello ${ }^{1}$ Stephen J. Greene ${ }^{2}$. Daniele Torres ${ }^{1} \cdot$ Michael Alderman $^{3} \cdot$ Joseph Vincent Bonventre $^{4}$. \\ Pietro Di Pasquale ${ }^{5} \cdot$ Luna Gargani $^{6} \cdot$ Anju Nohria $^{7}$. Gregg C. Fonarow ${ }^{8} \cdot$ Muthiah Vaduganathan $^{9} \cdot$ Javed Butler $^{10}$. \\ Salvatore Paterna ${ }^{1} \cdot$ Lynne Warner Stevenson $^{7} \cdot$ Mihai Gheorghiade $^{2}$
}

Published online: 29 April 2021

๑) Springer Science+Business Media, LLC, part of Springer Nature 2021

\section{Editorial Expression of Concern: Heart Fail Rev 20, 13-24 (2015). https://doi.org/10. 1007/s10741-014-9438-7}

The Editors-in-Chief would like to alert readers that for two articles included in this review (references 46 and $51[1,2]$ ) Editorial Expressions of Concerns have been published [3, 4] regarding potential duplication of data, and the loss of the underlying data. Readers are encouraged to closely examine the concern regarding the original data when interpreting the content and conclusions of the review article.

Stephen J. Greene, Gregg C. Fonarow, Muthiah Vaduganathan and Javid Butler agree with this Expression of Concern. Joseph Vincent Bonventre has not explicitly stated whether he agrees to this Expression of Concern. Gaspare Parrinello, Daniele Torres, Michael Alderman, Pietro Di Pasquale, Luna Gargani, Anju Nohria, Salvatore Paterna and Lynne Warner Stevenson have not responded to correspondence regarding this Expression of Concern. Mihai Gheorghiade is deceased.

The original article can be found online at https://doi.org/10.1007/ s10741-014-9438-7.

Gaspare Parrinello

gaspare.parrinello@unipa.it

1 Biomedical Department of Internal and Specialty Medicine, (Di.Bi.M.I.S.), A.O.U.P “Paolo Giaccone”, University of Palermo, Piazza delle Cliniche 2, 90,127 Palermo, Italy

2 Center for Cardiovascular Innovation, Northwestern University Feinberg School of Medicine, Chicago, USA

3 Department of Epidemiology and Population Health, Albert Einstein College of Medicine, Yeshiva University, New York, USA

4 Renal Division, Brigham and Women's Hospital, Harvard Medical School, Boston, USA

\section{Reference}

1. Parrinello G, Di Pasquale P, Licata G et al (2009) Long-term effects of dietary sodium intake on cytokines and neurohormonal activation in patients with recently compensated congestive heart failure. J Card Fail 15:864-873

2. Paterna S, Gaspare P, Fasullo S et al (2008) Normal-sodium diet compared with low-sodium diet in compensated congestive heart failure: is sodium an old enemy or a new friend? Clin Sci 114:221-230

3. Gary S (2013) Francis Notice of Concern, J Card Fail 19;(7):523. https://doi.org/10.1016/j.cardfail.2013.05.015

4. Expression of Concern: (2020) Normal-sodium diet compared with low-sodium diet in compensated congestive heart failure: is sodium an old enemy or a new friend? Clin Sci (Lond) 134(13):1841. https://doi.org/10.1042/CS-20070193_EOC

Publisher's Note Springer Nature remains neutral with regard to jurisdictional claims in published maps and institutional affiliations.

5 Division of Cardiology, GF Ingrassia Hospital, Palermo, Italy

6 Institute of Clinical Physiology, National Council of Research, Pisa, Italy

7 Cardiovascular Division, Brigham and Women's Hospital, Harvard Medical School, Boston, USA

8 Ronald Reagan-UCLA Medical Center, Los Angeles, USA

9 Department of Medicine, Massachusetts General Hospital, Harvard Medical School, Boston, USA

10 Division of Cardiology, Emory University, Atlanta, USA 